\title{
PROPOSTA DE DESENVOLVIMENTO DE SOFTWARE DE CONTA VINCULADA
}

\author{
Thiago dos Santos Nobre ${ }^{1}$ \\ Gerson de Sousa Batista ${ }^{2}$ \\ Francisco Silva Gomes ${ }^{3}$ \\ Luciene Pereira Braga ${ }^{4}$ \\ Juliana Lobato Lima ${ }^{5}$ \\ Djimara de Assis Rocha de Figueiredo 6
}

RESUMO: Este trabalho tem como objetivo geral propor um projeto de desenvolvimento de uma aplicação personalizada, utilizando a tecnologia da informação para auxiliar a Unir, Campus de Presidente Médici, no gerenciamento de Conta Vinculada, especificando as características mais relevantes do Software, levadas em consideração pelos gestores e fiscais de contrato, bem como analisar e documentar os requisitos necessários para o desenvolvimento do sistema. O problema da pesquisa é a ausência de uma aplicação personalizada, e diante disso foi necessário realizar a seguinte pergunta: quais são os requisitos indispensáveis para o desenvolvimento de um sistema de Gestão de Conta Vinculada? A hipótese da pesquisa é a consolidação das informações, demonstrando a importância do desenvolvimento de uma ferramenta informatizada e específica. O presente trabalho tem como justificativa a proteção dos direitos trabalhistas, considerando a essencialidade dos serviços terceirizados para a manutenção da instituição supracitada, que possui em seu quadro funcional, um número significativo de colaboradores, tornando-se indispensável o desenvolvimento de um sistema de gerenciamento eficiente de Conta Vinculada.

Palavras-chave: Terceirização. Conta Vinculada. Aplicação personalizada.

\section{INTRODUÇÃO}

A Tecnologia da Informação, quando aplicada de forma adequada, proporciona ao setor público, lucratividade e confiabilidade no acesso aos dados, auxiliando a organização, de acordo com os recursos tecnológicos disponibilizados para a cada situação em particular,

\footnotetext{
${ }^{I}$ Formado em Análise e Desenvolvimento de Sistemas pelo Instituto Federal de Rondônia. E-mail: tsnobre9o@gmail.com.

${ }^{2}$ Formado em Direito pela Universidade Estadual do Piauí e em Letras Portuguesa pela Universidade Federal do Piauí.

3 Formado em Licenciatura Plena em Pedagogia pela Universidade Estadual do Piauí. Email:gomesfsil@gmail.com.

4 Formada em Licenciatura Plena em Pedagogia pela Universidade Estácio de Sá. E-mail: lucienepb@gmail.com.

${ }^{5}$ Formada em Ciências Sociais pela Universidade Federal do Amapá. E-mail: Julianalobato@hotmail.com.

${ }^{6}$ Formada em Licenciatura Plena em Matemática pela Universidade Estadual do Piauí- UESPI. E-mail: djimararocha@hotmail.com.
} 
provendo a Administração Pública com estatística e relatórios dos dados gravados no banco de dados.

Inicialmente, para a concretização deste trabalho foram levantados os requisitos básicos para o desenvolvimento do sistema com base na experiência dos usuários e dos conhecimentos adquiridos através das planilhas eletrônicas e dos procedimentos realizados durante a execução e fiscalização dos contratos administrativos, identificando as principais necessidades dos Gestores e Fiscais dos contratos. Diante disso, percebeu-se a necessidade de desenvolver uma aplicação com características específicas, facilitando o gerenciamento das Contas Vinculadas. Algumas situações, dentre outras, serviram para estimular o desenvolvimento deste trabalho, como a ausência de meios práticos e eficientes de controlar a entrada e saída de valores da Conta Vinculada, não obtendo dados precisos das retenções de acordo com as notas fiscais enviadas para pagamento num determinado período de tempo, em virtude disso, o presente trabalho tem como objetivo propor o desenvolvimento de uma aplicação personalizada que visa suprir essa deficiência.

No decorrer do desenvolvimento deste trabalho, primeiramente, procurou-se definir o que é terceirização. Num segundo momento, explicou a definição de responsabilidade subsidiária. Em terceiro, como funciona o processo de contratação de serviços com alocação de mão de obra com dedicação exclusiva na Esfera Federal. Num quarto momento, foi crucial entender a definição da Conta-Depósito Vinculada, bloqueada para Movimentação. Num quinto momento, foram enumeradas as possíveis tecnologias que podem ser utilizadas para o desenvolvimento do sistema e as aplicações que poderão dar suporte na codificação do software voltado para a plataforma web. Por último, foram apresentados através do Diagrama de Caso de Uso os resultados extraídos durante o levantamento de requisitos do sistema com base na Engenharia de Software.

No decorrer desse tempo, a pesquisa bibliográfica teve fundamental importância no entendimento e diferenciação dos papéis dos agentes participantes na fiscalização e execução de contrato, assim como em todo o desenvolvimento do trabalho, como, por exemplo, nas definições dos itens do parágrafo anterior. Assim como, também, a experiência dos gestores e fiscais dos contratos colaborou para o entendimento e catalogação das funcionalidades do sistema. 


\title{
2 DESENVOLVIMENTO
}

\section{I Definição de Terceirização}

De acordo com Lopes (2018 apud FERRAZ, 2007, p. 38), o marco legal da terceirização no setor público é a publicação do Decreto-Lei no 200 de 25 de fevereiro de 1967, permitindo em seu Art. ı, § $7^{\circ}$ a execução de forma descentralizada pela iniciativa privada de atividades da Administração Pública. Assim o Decreto descreve:

\begin{abstract}
Art. Io. A execução das atividades da Administração Federal deverá ser amplamente descentralizada. $\S 7^{\circ}$ - Para melhor desincumbir-se das tarefas de planejamento, coordenação, supervisão e controle e com o objetivo de impedir o crescimento desmesurado da máquina administrativa, a Administração procurará desobrigar-se da realização material de tarefas executivas, recorrendo, sempre que possível, à execução indireta, mediante contrato, desde que exista, na área, iniciativa privada suficientemente desenvolvida e capacitada a desempenhar os encargos de execução (BRASIL, 1967).
\end{abstract}

O Decreto-Lei no 200 foi o precursor para a edição de Leis como a 5.645/7o que estabelecia, em seu $3^{\circ}$ artigo, atividades prioritárias para contratação com o setor privado como, por exemplo, conservação, limpeza, vigilância e transporte (Lopes, 2018, p. 39).

Com a evolução da Terceirização no Brasil, seja no Setor Público ou Privado, vários autores conceituaram a Terceirização e para Martins (2012, p. 192), ela consiste:

[...] na possibilidade de contratar terceiro para a realização de atividades que não constituem o objeto principal da empresa. Essa contratação pode compreender tanto a produção de bens, como de serviços, como ocorre na necessidade de contratação de empresa de limpeza, de vigilância ou até para serviços temporários.

Desse modo, a terceirização tem como objetivo transferir atividades meio à terceiros, ficando a organização concentrada em sua atividade principal. Nesse contexto, a terceirização também pode ser definida como todo processo de contratação de trabalhadores por empresa interposta, cujo objetivo último é a redução de custos com a força de trabalho e/ou a externalização dos conflitos trabalhistas (MARCELINO; CAVALCANTE, 2012).

Portanto, essa relação trilateral, de um lado o contratante e do outro lado a contratada como intermediador, a organização pode focar em sua atividade principal, objetivando aumentar a qualidade e a produtividade, reduzindo assim os custos com a contratação direta de mão de obra. 


\subsection{Responsabilidade Subsidiária}

A Súmula $\mathrm{n}^{\mathrm{o}}$ 33I do TST, inciso IV, possui o seguinte entendimento:

IV - O inadimplemento das obrigações trabalhistas, por parte do empregador, implica a responsabilidade subsidiária do tomador dos serviços quanto àquelas obrigações, desde que haja participado da relação processual e conste também do título executivo judicial.

O inciso IV da Súmula $\mathrm{n}^{\mathrm{o}}$ 33I esclarece o significado de responsabilidade subsidiária, colocando em posição de subsidiariedade quanto as obrigações trabalhistas, a contratante em relação à contratada de serviços terceirizados, quando esta última não pagar os créditos trabalhistas dos seus colaboradores.

Portanto, para uma terceirização ser considerada lícita, deverá ser ausente a subordinação e a pessoalidade dos trabalhadores com o contratante dos serviços, devendo manter o vínculo empregatício somente com a contratada, conforme entendimento do inciso I da Súmula no 33 I do TST. E caso fique caracterizado o vínculo trabalhista com a empresa tomadora, é estabelecido o vínculo empregatício, e, logo, incide sobre o contrato de trabalho todas as normas pertinentes à categoria do trabalho (SILVA, 20II).

Para exemplificar a repercussão da terceirização, a Coordenadoria de Estatística e Pesquisa do TST (CESTP) publicou um relatório com o ranking das 20 maiores litigantes na Suprema Corte do Trabalho em 30 de setembro do ano de 2019, apontando uma estatística de IIo.II 8 processos referente a terceirização, que corresponde a 32\% do total de 344.416 processos em tramitação no Tribunal, ficando a União no rol das quatro primeiras posições: Petrobrás com I2.955 processos; Banco do Brasil com II.039; Caixa com I0.198; e a União com 9.032 processos. E dos 20 assuntos mais abordados nos processos dentro do TST, somente o tema Terceirização envolvendo o Ente Público, não sendo levados em conta outros temas de mesmo teor e relevância, ocupa o sexto lugar dos processos em tramitação, com cerca de 7,40\% do quantitativo total (CESTP, 2019).

Com base nos dados anteriores, percebe-se que a utilização excessiva da terceirização é algo que deve ser vista com grande crítica e preocupação, pois os números demonstram certa precarização nas relações trabalhistas, pois não havendo proteção por 
parte do Administrador Público, então cabendo ao trabalhador recorrer somente ao Judiciário para proteção dos seus direitos.

\title{
2.3 Processo de Contratação na Esfera de Serviço na Esfera Federal
}

A obrigatoriedade da Administração Pública realizar licitação está prevista na Constituição Federal (CF) de 1988 em seu art. 37, inciso XXI, que assim define:

\begin{abstract}
XXI - ressalvados os casos especificados na legislação, as obras, serviços, compras e alienações serão contratados mediante processo de licitação pública que assegure igualdade de condições a todos os concorrentes, com cláusulas que estabeleçam obrigações de pagamento, mantidas as condições efetivas da proposta, nos termos da lei, o qual somente permitirá as exigências de qualificação técnica e econômica indispensáveis à garantia do cumprimento das obrigações.
\end{abstract}

Desta maneira, quando uma empresa particular pretende adquirir bens e contratar obras ou serviços, o particular possui total liberdade em manter relações comerciais com seus fornecedores, porém com a Administração Pública é diferente, devendo seguir um rito processual, podendo ser através de compra direta, sendo a regra, e a dispensa ou inexigibilidade de licitação, a exceção, expressamente prevista em lei.

O inciso XXVII do artigo 22 da CF de 1988 define que compete privativamente à União legislar sobre:

XXVII - normas gerais de licitação e contratação, em todas as modalidades, para as administrações públicas diretas, autárquicas e fundacionais da União, Estados, Distrito Federal e Municípios, obedecido o disposto no art. 37, XXI, e para as empresas públicas e sociedades de economia mista, nos termos do art. I73, § I ${ }^{\circ}$, III;

Portanto, o supracitado inciso deixa claro que somente a União poderá legislar sobre normas gerais de licitação, devendo todos os entes da administração pública direta e indireta seguir tais normas, inferindo-se, em vista disso, esses mesmos entes não estão impedidos de editar normas complementares de carácter específico, contudo não poderão inovar no ordenamento jurídico.

No artigo 37 da CF de 1988, todos os entes da administração pública obedecerão aos princípios constitucionais no trato com a coisa pública, como o da legalidade, impessoalidade, moralidade, publicidade e eficiência, e também o seguinte: 
XXI - ressalvados os casos especificados na legislação, as obras, serviços, compras e alienações serão contratados mediante processo de licitação pública que assegure igualdade de condições a todos os concorrentes, com cláusulas que estabeleçam obrigações de pagamento, mantidas as condições efetivas da proposta, nos termos da lei, o qual somente permitirá as exigências de qualificação técnica e econômica indispensáveis à garantia do cumprimento das obrigações.

Diante do fato da obrigatoriedade do seguimento de princípios e regras constitucionais, surge, então, a Lei Geral das Licitações, a Lei 8.666 de 1993 que regulamenta o inciso XXI do art. 37 da Constituição Federal de 1988. Posteriormente, diversas outras leis foram criadas no intuito de institucionalizar novos instrumentos licitatórios complementares a lei 8.666/93, em especial, a lei 10.520 de 2002, editada para regular o pregão, uma modalidade de licitação, sendo através desta que origina os Contratos de Terceirização na Fundação Universidade Federal Rondônia com dedicação de mão de obra exclusiva.

A Lei $n^{0} 8.666$ de 1993 institui as modalidades concorrência, tomada de preços, convite, concurso e leilão. A Lei no 13.303 de 2016 além de estabelecer o estatuto jurídico,

também cria regras próprias de licitação, dispensa, inexigibilidade e contratação das empresas públicas, sociedade de economia mista e de suas subsidiárias. Além dessas leis, vários outros institutos legais também podem ser citados em relação as licitações.

\subsection{Conta Deposito Vinculada, Bloqueada para Movimentação}

Conforme mencionado anteriormente, o inciso IV da Súmula no 33 I do TST possui o entendimento jurídico que a Administração Direta e Indireta possui responsabilidade subsidiária relativo às verbas trabalhistas quando a administração pública cometer falhas na fiscalização contratual. Diante disso, a Conta Depósito Vinculada para movimentação, comumente chamada somente de Conta Vinculada, é uma conta que a Administração Pública vai depositar alguns encargos trabalhistas e não irá pagar diretamente a empresa contratada, depositando em uma Conta Bancária em nome da empresa, vinculando-a ao contrato, em que somente a Administração Pública irá autorizar a movimentação.

Por intermédio da Conta Vinculada, a Administração Pública não paga o valor integral da Fatura ou Nota Fiscal, sendo os encargos descontados e depositados em conta bancária. A contratada fica impedida de movimentar livremente o saldo disponível, sendo 
liberado pela Administração Pública conforme a empresa comprovar os pagamentos dos encargos trabalhistas de seus colaboradores, proporcionalmente ao tempo em que estiver disponibilizado ao contrato administrativo. $\mathrm{O}$ valor depositado ainda pertence à empresa, porém a contratada só vai receber os valores quando houver autorização expressa da Administração Pública, conforme está regulamentado pela IN no 5 de 26 de maio de 2017 .

A implantação da Conta Vinculada deve está especificada no edital de licitação com todas as suas regras, inclusive a minuta deverá está disponível no processo de licitação para que a contratada fique sabendo da obrigação de assinar, concordando com os termos de uso e abertura desse tipo de conta em seu CNPJ. A utilização da Conta Vinculada é uma forma de amenizar a responsabilidade subsidiária da Administração Pública em face aos encargos trabalhistas, em virtude do inadimplemento da contratada, pois conforme já demonstrado, a União tem sido alvo constante de processos trabalhistas envolvendo pagamento de valores pecuniários de teor trabalhista.

Dos valores retidos, não são quaisquer valores que vão ser retidos para a Conta Vinculada, mas somente aquelas verbas trabalhistas expressamente especificadas no Caderno de Logística de Conta Vinculada do ano de 2018, conforme regulamentado no artigo ı 8 da IN no os do Ministério do Planejamento. As verbas trabalhistas retidas são aqueles referentes às férias e um terço constitucional de férias, o décimo terceiro salário, a multa sobre FGTS e as de carácter rescisórias.

Segundo o Caderno de Logística de Conta Vinculada (2018), as devoluções dos valores da Conta Vinculada somente podem ocorrer quando surge o pagamento de férias, I3ํ salário ou mesmo rescisão de contrato e, portanto, a empresa tem a obrigação de comprovar através de documentos que foram pagos os valores ao funcionário e que a situação da empresa encontra-se regular perante os órgãos fiscalizadores. Assim posto, a Administração Pública fará um ofício para Instituição Bancária, autorizando o valor da parcela devida, proporcionalmente ao período em que o trabalhador esteve vinculado ao contrato.

A liberação de valores depositados em Conta Vinculada ocorrerá segundo as alíneas I. 5 e r.6 do Anexo VII-B da IN n ${ }^{\circ} 5$ de 2017, da seguinte forma: "parcial e anualmente, pelo valor correspondente ao décimo terceiro salário dos empregados vinculados ao contrato, 
quando devido; parcialmente, pelo valor correspondente às férias e a $1 / 3$ (um terço) de férias previsto na Constituição, quando do gozo de férias pelos empregados vinculados ao contrato; parcialmente, pelo valor correspondente ao décimo terceiro salário proporcional, às férias proporcionais e à indenização compensatória porventura devida sobre o FGTS, quando da dispensa de empregado vinculado ao contrato; e ao final da vigência do contrato, para o pagamento das verbas rescisórias" (BRASIL, 2017, p. 74).

\subsection{Sistema de Informação para o Gerenciamento de Compras}

Na Figura I, a UNIR disponibiliza o SIGEC (Sistema de Gestão de Compras) em seu site oficial pela Diretoria de Compras e Licitações para disponibilizar todos os documentos gerados durante o processo de licitação e execução dos contratos administrativos. É o meio pelo qual os servidores e interessados podem extrair informações oficiais e relevantes, obedecendo a Lei de Acesso à Informação.

Figura I - Sistema de Gestão de Compras

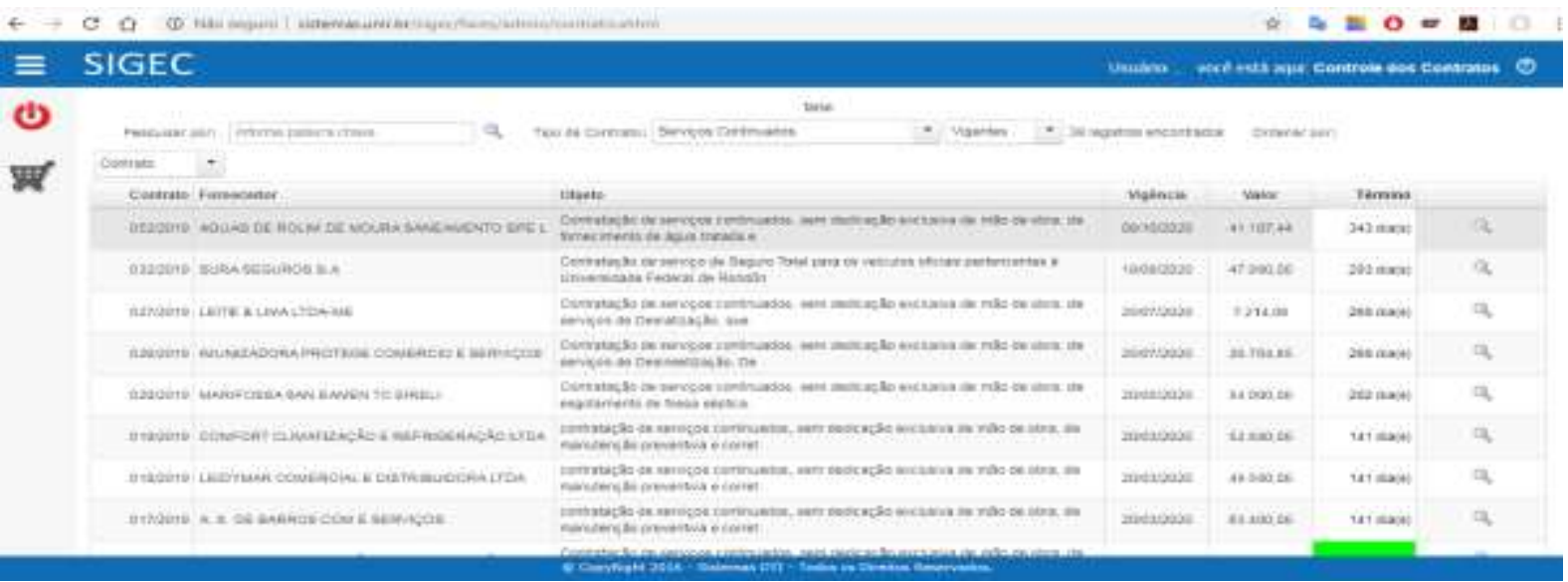

Fonte: disponível em: 〈http://abre.ai/sigec $>$. Acesso em or de nov. de 2019.

\subsection{Sistemas Existentes para a Gestão de Contas Vinculadas}

Recentemente, no dia 17 de setembro de 2019, fora disponibilizado uma ferramenta em formato Excel pela Empresa Brasileira de Serviços Hospitalares - EBSERH, com utilização de macros e codificação em VBA (Virtual Basic for Applications), com o propósito de facilitar a gestão dos saldos das Contas Vinculadas. Conforme pode ser 
verificado na Figura 2, tal ferramenta foi de extrema importância para o levantamento de requisitos, permitindo ter uma visão mais clara das características essenciais de um Sistema de Gestão de Conta Vinculada. Devido conter direitos autorais, a ferramenta não está disponível de forma online, mas pode ser consultado o manual no site oficial da EBSERH para conhecimento das funcionalidades disponíveis.

Figura 2 - Ferramenta de gestão de saldo das Contas Vinculadas

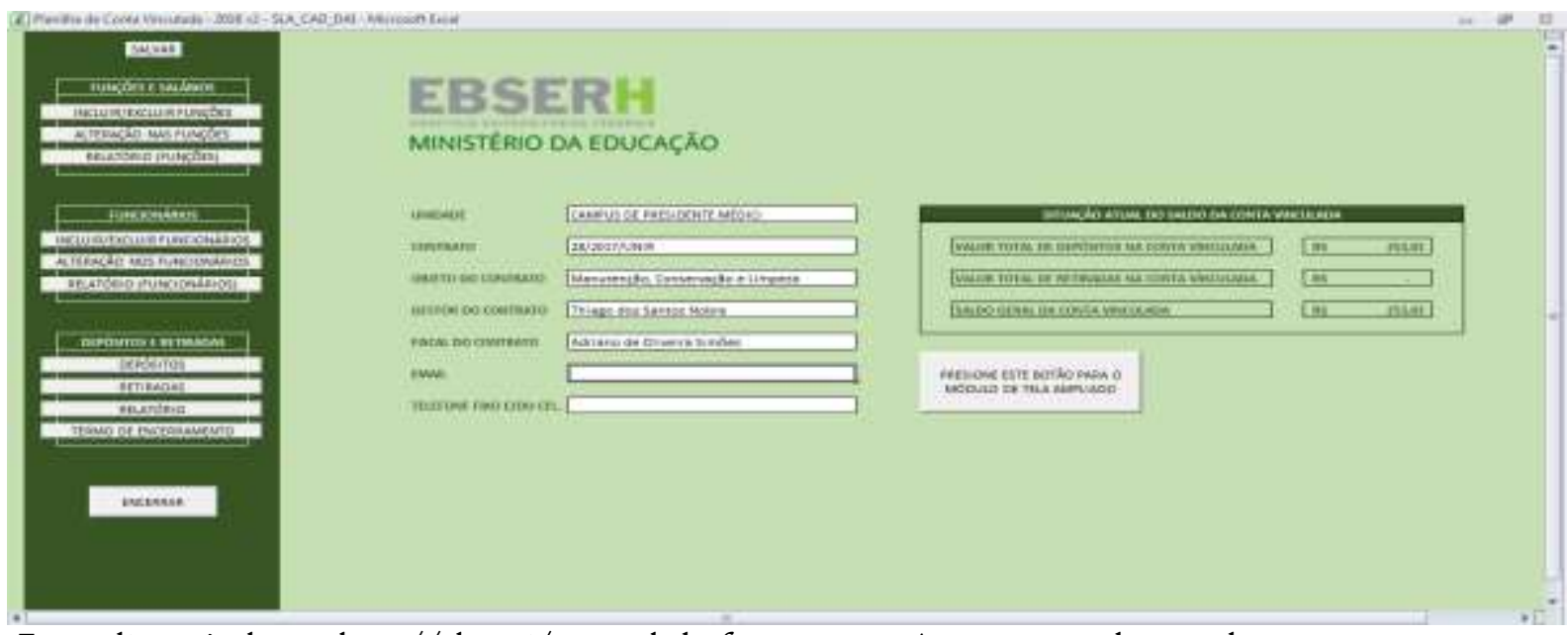

Fonte disponível em: $\langle$ http://abre.ai/manual_da_ferramenta $>$. Acesso em or de nov. de 2019.

\subsection{Tecnologia Disponível Para o Desenvolvimento do Sistema}

\subsection{Bootstrap}

Bootstrap é um framework front-end para desenvolvimento web, criado por volta de 2010 por Mark Otto e Jacob, funcionários do Twitter, com o propósito de padronizar as interfaces gráficas dos sites, impedindo várias inconsistências. Lançado no segundo semestre de 20II, o framework logo ganhou notoriedade, sendo uma das ferramentas mais populares no Github já no começo de 2012.

O framework Bootstrap conta com uma série de recursos com a utilização do HTML, CSS e JavaScript, pronto para implementar recursos como dropdowns, carrosséis e outros, sendo utilizado por muitos sites famosos, tanto no Brasil, como no exterior (Becode, 2017). 
Mas para trabalhar com esta ferramenta front-end é necessário dominar o básico das linguagens HTML, CSS e JavaScript.

\subsection{I.I HTML}

O termo HTML é o acrônimo de HyperText Markup Language, ou em português como Linguagem de Marcação de Hipertexto. O HTML é uma linguagem utilizada para estruturar conteúdo na web, criando significado e organizando as informações dos websites. Aliada ao JavaScript e ao CSS, tornam-se uma poderosa ferramenta para World Wide Web (WWW).

\subsubsection{CSS}

O termo CSS em inglês significa "Cascading Style Sheets", que em português significaria como "Folha de Estilo em Cascatas". É uma linguagem amplamente utilizada juntamente com as linguagens de marcação, o HTML ou XHTML. Essa linguagem permite que páginas web possuam todos os estilos necessários, como, por exemplo, cores, espaçamentos, tamanhos e tipos de fontes, entre outros. No desenvolvimento poderá ser utilizada a versão 3 , por ser a mais recente.

\subsubsection{JavaScript}

Nesse contexto de linguagem, o JavaScript já é considerado uma linguagem de programação que permite implementar funcionalidades mais complexas nas páginas web. É uma linguagem de programação client-side, ou seja, do lado do cliente. É amplamente utilizada para controlar componentes do HTML e do CSS, manipulando comportamentos de páginas web, por exemplo, um submenu, quando passa o mouse em um item do menu (GITHUB, 2019).

$\mathrm{Na}$ programação web, o desenvolvimento funciona, basicamente, em três camadas, com o HTML fica com as informações, o CSS realiza as formatações necessárias na página e o comportamento com a linguagem de programação JavaScript, funcionando como a terceira camada de desenvolvimento, manipulando as duas anteriores (GITHUB, 2019). 


\subsubsection{Laragon}

O Laragon é um ambiente de desenvolvimento web gratuito e simples, mas completo. O pacote de instalação já vem com todas as ferramentas e recursos necessários e já pré-configurados, diminuindo o risco de conflito de porta entre as aplicações. Abaixo estão especificadas as principais ferramentas disponíveis neste ambiente de desenvolvimento.

2.6.2.1 Apache

Apache é um servidor de código aberto, mantido pela Apache Software Foundation, que alimenta cerca de $46 \%$ de todos os sites hospedados na internet, permitindo os sites mostrarem e manterem seus conteúdos na internet, sendo denominado de "servidor de internet”. É um servidor confiável, por ser um dos mais antigos da internet, sendo a sua primeira versão lançada há mais de 20 anos, transmitindo estabilidade e credibilidade aos usuários e desenvolvedores de software (Hostinger, 2019).

\subsubsection{MySQL}

O MySQL é uma Sistema Gerenciador de Banco de Dados (SGBD) relacional, assim como SQLServer ou Oracle Database, open source, que utiliza a linguagem SQL Structured Query Language, ou em português, Linguagem de Consulta Estruturada, como linguagem de comunicação com o banco de dados, pois é diferente de Banco de Dados Relacional, que é uma coleção de dados estruturados em forma de tabelas (Hostinger, 2019).

\subsubsection{PHP}

PHP é um acrônimo de "Hypertext Preprocessor", ou em português como PréProcessador de Hipertexto, sendo uma das linguagens de programação mais utilizadas do lado do servidor, possuindo uma comunidade bastante ativa. Dentre as vantagens de utilizar essa linguagem está na facilidade de aprendizagem, de manuseio, open source, e, é compatível com quase todos os sistemas operacionais existentes, o que diminui bastante os custos de desenvolvimento do software. Por ser considerada uma linguagem de script, que 
pode rodar tanto do lado do servidor quanto do lado do cliente, ela serve para automatizar a execução de tarefas num ambiente de tempo de execução especial, criando websites dinâmicos e integrando o sistema como um todo (Hostinger, 2019).

\subsubsection{HeidiSQL}

O HeidiSQL é uma aplicação cliente, livre e de fácil aprendizado, permitindo visualizar e editar os dados do banco de dados MySQL ou outros SGBDs relacionais disponíveis. É uma das ferramentas disponíveis para o ambiente de desenvolvimento Laragon, permitindo ao usuário ter uma ferramenta completa com poucos cliques no momento da instalação e em português.

\subsubsection{Atom}

Atom é um editor gratuito, de código de aberto e leve, desenvolvido e mantido pelo GitHub. É customizável e com farta documentação disponível. É um ótimo editor para o desenvolvimento web, permitindo trabalhar com o SQL, HTML, CSS, JavaScript e PHP.

\subsubsection{BRModelo}

O brModelo é uma aplicação open source de modelagem de Banco de Dados, desenvolvida por Carlos Henrique Cândido, bastante utilizada no meio acadêmico. Para rodar esse software é preciso a instalação do Java Runtime Environment (JRE) r.8. A aplicação em si já um autoexecutável, portanto, não há necessidade de instalação do programa no próprio sistema operacional.

\subsubsection{Astah Community}

Astah Community é um software que é gratuito apenas na sua versão antiga, pois atualmente, encontra-se na versão paga. É um software desktop voltado para a modelagem de diagramas UML (Unified Modeling Language). Sendo uma ferramenta simples e prática na elaboração dos diagramas que auxiliam o entendimento e o desenvolvimento de qualquer aplicação. Para este trabalho, ele foi utilizado para a confecção do Diagrama de Caso de Uso. 


\section{RESULTADOS}

Utilizando-se da Engenharia de Software (que é uma área da computação voltada para especificação, desenvolvimento, manutenção e criação de software, visando organização, produtividade e qualidade) para realização do levantamento de requisitos para desenvolvimento das principais funcionalidades do sistema de gestão de Conta Vinculada, empregou-se o Diagrama de Caso Uso com intuito de construir uma visão genérica e abstrata do sistema, obtendo o seguinte resultado:

Figura 3 - Diagrama de Caso de Uso

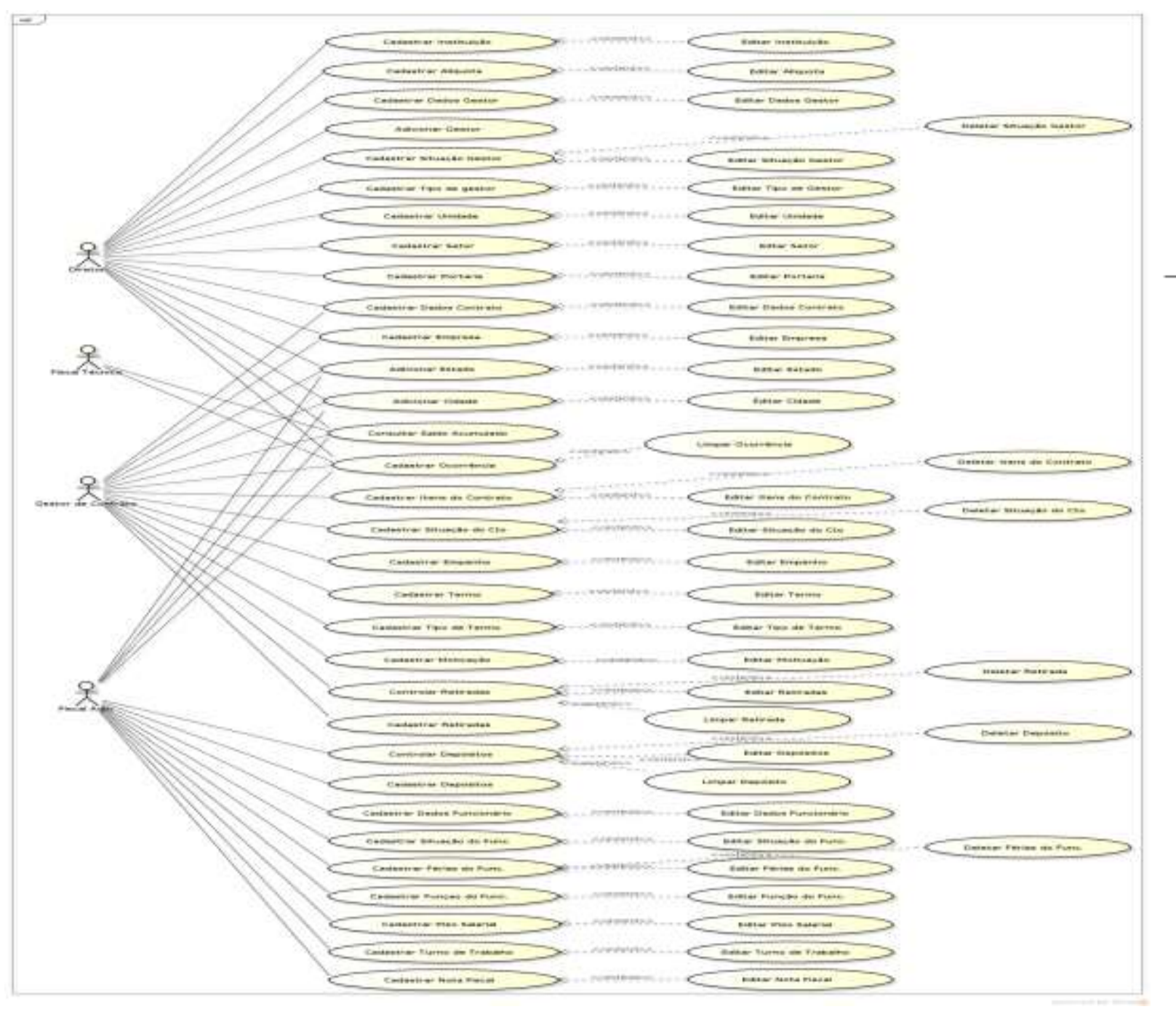

Fonte: próprio autor. 


\section{RESULTADOS}

Com os resultados obtidos com este trabalho, pode-se concluir que este sistema conseguirá concretizar as seguintes características:

a) automação do processo de cálculo de entrada e saída de valores da Conta Vinculada ao seu respectivo Contrato Administrativo e nota fiscal;

b) economia de tempo no lançamento dos dados dos gestores, fiscais, contratos e funcionários disponibilizados para os contratos administrativos;

C) possibilita a impressão de relatórios mensais para a gestão e fiscalização dos contratos administrativos;

d) disponibilização de um histórico de lançamento das informações com dados precisos, no tempo certo e de qualquer lugar, por ser um sistema web;

e) possibilita uma maior confiabilidade dos dados que estiverem disponibilizados na base de dados, tornando o processo de consultas mais eficientes, além de minimizar os erros de lançamento por parte dos usuários;

f) viabiliza a utilização de uma única base de dados compartilhada.

g) torna-se possível a redução da insegurança dos gestores e fiscais dos contratos quanto aos valores relacionados às retenções e devoluções que serão inseridos na base de dados;

h) concretização do gerenciamento dos saldos das Contas Vinculadas aos contratos administrativos realizados entre empresas privadas e a Unir Campus de Presidente Médici, de forma eficiente e eficaz, propiciando economia de papel, tempo e recursos humanos da instituição pública.

i) E por fim, o sistema deve possuir um sistema de autenticação para que somente usuários previamente cadastrados e com permissões específicas podem realizar consultas, inserções, alterações e apagar dados na base de dados do sistema.

Portanto, por todos os aspectos acima mencionados, é através da utilização do sistema de informação para o desenvolvimento de uma aplicação de gerenciamento da Conta Vinculada, é possível obter eficiência do Serviço Público, mesmo que este sistema seja uma parte para a resolução dos problemas relacionados à gestão dos recursos públicos.

\section{CONSIDERAÇÕES}

Com a hipótese levantada, durante a fase de levantamento de requisitos foi possível consolidar informações dos requisitos indispensáveis para o desenvolvimento da aplicação, demonstrando a importância do desenvolvimento de uma ferramenta informatizada, que tem como propósito auxiliar 
no controle e gerenciamento de funcionários disponibilizados aos contratos administrativos, assim como as retenções e retiradas de valores da conta vinculada.

Deste modo, o objetivo geral deste trabalho, que era de uma proposta de desenvolvimento de software, foi concretizado, tendo como resultado quarenta funcionalidades que podem ser desenvolvidas para o sistema em questão, disponibilizando-o para Unir, Campus de Presidente Médici.

Já em relação aos objetivos específicos foram atingidos no decorrer deste trabalho, distribuídos entre as seções, com o auxílio da pesquisa bibliográfica. E o levantamento de requisitos foi realizado com base na experiência dos gestores e fiscais de contratos, sendo representados através do Diagrama de Caso de Uso, técnica utilizada na Engenharia de Software e detalhado em tabela, posteriormente.

Os benefícios obtidos através da utilização deste sistema é progressivo e vai se maximizando de acordo como o banco de dados é alimentado e, também, de acordo com as melhorias forem sendo implementadas na aplicação. Por se tratar de uma proposta de desenvolvimento de uma aplicação web personalizada, que deve seguir um ciclo de desenvolvimento de software, no decorrer da execução do projeto, podem ser necessárias algumas melhorias ou implementações no levantamento de requisitos deste trabalho.

REFERÊNCIAS

BECODE. Bootstrap: o que é, porque usar e como começar com o framework. Disponível em: 〈http://abre.ai/anC2>. Acesso em: 20 de outubro de 2019.

BRASIL. Ministério do Planejamento, Desenvolvimento e Gestão. Secretaria de Gestão. Cartilha sobre Conta-Depósito Vinculada - bloqueada para movimentação, 2018. Orientações básicas sobre a operacionalização da Conta Vinculada nos termos da alínea "a" do item I.I do Anexo VII-B e do Anexo XII da Instrução Normativa no 5, de 26 de maio de 2017. Disponível em: 〈http://abre.ai/arGi〉. Acesso em: 03 de setembro de 2019.

. Ministério do Planejamento, Desenvolvimento e Gestão. Secretaria de Gestão.

Portal de Compras do Governo Federal. Dispõe sobre as regras e diretrizes do procedimento de contratação de serviços sob o regime de execução indireta no âmbito da Administração Pública federal direta, autárquica e fundacional. Instrução Normativa $\mathbf{n}$ ㅇ 05, de 26 de maio de 2017. Disponível em: 〈http://abre.ai/atpa〉. Acesso em: 03 de setembro de 2019 .

. Presidência da República. Casa Civil. Subchefia para Assuntos Jurídicos.

Constituição da república federativa do Brasil de 1988. Brasília, 1988. Disponível em: $\langle$ http://abre.ai/arGC〉. Acesso em: 03 de setembro de 2019. 
- Presidência da República. Casa Civil. Subchefia para Assuntos Jurídicos. Lei no 8.666 de 21 junho 1993. Regulamenta o art. 37, inciso XXI, da Constituição Federal, institui normas para licitações e contratos da Administração Pública e dá outras providências. Disponível em: 〈http://abre.ai/argG〉. Acesso em: 03 de setembro de 2019.

. Tribunal Superior do Trabalho. Súmula no 331 do TST de 1993. Revisão da Súmula no 256. Disponível em: 〈http://abre.ai/aqzv〉. Acesso em: 03 de setembro de 2019.

CESTP. Movimentação Processual do TST. Setembro de 2019. Disponível em: 〈http://abre.ai/argB >. Acesso em: or de novembro de 2019.

GITHUB. O que é JavaScript? Controlando o comportamento do HTML e o CSS. Disponível em: 〈http://abre.ai/aoI3〉. Acesso em: 24 de outubro de 2019.

Hostinger. O que é Apache? Uma visão aprofundada do servidor Apache. Disponível em: 〈http://abre.ai/aoJK〉. Acesso em: 24 de outubro de 2019 .

O Que É MySQL? Guia Para Iniciantes. Disponível em: 〈http://abre.ai/aoKq〉. Acesso em: 24 de outubro de 2019 .

- O Que é PHP? Guia Básico de Programação PHP. Disponível em: $\langle$ http://abre.ai/aoKH〉. Acesso em: 24 de outubro de 2019.

JKOLB. NBR ISO/IEC 9126-r. Disponível em: 〈http://abre.ai/aoIs〉. Acesso em: 24 de outubro de 2019 .

LOPES, Bruno Lobão. Proposta de modelo para avaliação da gestão da Conta Vinculada de contratos de terceirização em IFES, baseada na Teoria do Stakeholder e no Performance Prism: um Estudo de Caso. Disponível em: 〈http://abre.ai/arD9〉. Acesso em: 27 de setembro de 2019 . 